\title{
Medical treatment of nystagmus and its visual consequences
}

\author{
John S Stahl MD PhD Gordon T Plant FRCP ${ }^{1} \quad$ R John Leigh MD
}

For us to see clearly the details in our visual world, images must be held quite still upon the retina, especially the central part (the fovea). For reading, which concerns detection of high spatial frequencies, image motion must be less than about $5^{\circ} /$ second $^{1}$. If image drift substantially exceeds this limit, visual acuity will decline and we may experience the illusion that the world is moving (oscillopsia). In health, three main mechanisms hold the line of sight steady so that our view of the world is clear and stable $^{2}$. The first is 'fixation', which has two distinct components - the visual system's ability to detect retinal image drift and programme corrective eye movements, and the ability to suppress unwanted eye movements that would take the eye away from the target. The second mechanism is the vestibulo-ocular reflex, by which the motion detectors of the inner ear promptly initiate eye movements to compensate for head perturbations, such as occur during locomotion. The third mechanism is the gaze-holding system, which makes it possible to hold the eyes at an eccentric position (e.g. in lateral gaze).

If any of the three mechanisms that normally act to hold gaze steady malfunctions, the eyes may start to drift away from the object of regard, and corrective rapid eye movements may be made. Thus, nystagmus may be defined as repetitive to-and-fro involuntary eye movements that are initiated by slow drifts of the eye. It is important to realize that some forms of nystagmus are normal. Thus, nystagmus that occurs during rotation of the body in space acts to preserve clear vision. In pathological nystagmus, however, drifts of the eyes away from the target degrade vision. In one form, pendular nystagmus, the drifts consist of a to-andfro sinusoidal oscillation. More commonly, nystagmus consists of alternation of unidirectional drifts away from the target and corrective fast movements (saccades) which momentarily bring the visual target back to the fovea; this is jerk nystagmus.

Department of Neurology, Veterans Affairs Medical Center, and University Hospitals, Case Western Reserve University, Cleveland, Ohio 44106, USA; 'Department of Neurology, Guy's \& St Thomas' Hospitals, London, UK

Correspondence to: R John Leigh MD, Department of Neurology, University Hospitals, 11100 Euclid Avenue, Cleveland, Ohio 44106-5040, USA

E-mail: rj14@po.cwru.edu
Nystagmus should be distinguished from inappropriate saccades that disrupt steady fixation. Saccades produce high-speed movement of images upon the retina - too high for clear vision - and several physiological mechanisms exist to prevent perception of the smeared retinal signal due to the saccade. However, patients in whom inappropriate saccades repeatedly misdirect the fovea often complain of difficulty with reading.

\section{Box 1 Medical strategies for treating nystagmus and its visual consequences \\ - Methods that place the eye in a position in which nystagmus is minimized \\ - Optical and electronic methods for negating the visual consequences of the nystagmus \\ - Procedures for weakening the extraocular muscles \\ - Application of somatosensory or auditory stimuli to suppress nystagmus \\ - Drugs that suppress some forms of nystagmus.}

Five main approaches to treating pathological nystagmus and its visual consequences are summarized in Box 1. For a fuller discussion of the clinical features, pathogenesis and treatment of nystagmus, the reader is referred to a recent textbook on eye movements ${ }^{2}$.

\section{METHODS THAT PLACE THE EYE IN A POSITION IN WHICH NYSTAGMUS IS MINIMIZED}

In patients whose nystagmus is suppressed by viewing a near target, convergence prisms will often improve vision. This is especially the case in some patients with congenital nystagmus, when the improvement of vision may be appreciable. An arrangement that is often effective is 7.00 diopter base-out prisms with -1.00 diopter spheres added to compensate for induced accommodation ${ }^{3}$. The spherical correction is not usually required in presbyopic individuals. Some patients with acquired nystagmus also benefit ${ }^{4}$, and in patients whose nystagmus is worse during near viewing, base-in prisms may help. In patients whose nystagmus is quieter when the eyes are moved into a particular position in the orbit (the 'null region') prisms only rarely help, since most patients use head-turns to bring their eyes to the quietest position. 


\section{OPTICAL AND ELECTRONIC METHODS FOR NEGATING THE VISUAL CONSEQUENCES OF THE NYSTAGMUS}

Rushton and Cox described an optical system that stabilizes images upon the retina ${ }^{5}$. This system consists of a highpositive-power spectacle lens worn in combination with a high-negative-power contact lens. The system rests on the principle that stabilization of images on the retina is achieved if the spectacle lens focuses the primary image close to the centre of rotation of the eye. Such images, however, are defocused, and a contact lens is required to extend back the focus onto the retina. Since the contact lens moves with the eye, it does not negate the effect of retinal image stabilization produced by the spectacle lens. With such a system it is possible to achieve up to $90 \%$ stabilization of images upon the retina. There are several limitations to this system ${ }^{6}$. The first is that it disables all eye movements (including the vestibulo-ocular reflex and vergence), so that it is only useful while the patient is stationary and views monocularly. Another limitation is that the field of view is limited. A third is that patients with ataxia or tremor (such as those with multiple sclerosis) have difficulty inserting the contact lens. We have found that, in selected patients, a modification of the device, which uses soft contact lenses and attempts to provide lower amounts of retinal image stabilization, may prove useful for limited periods of time - for example, if the patient wishes to watch a television programme ${ }^{6}$.

A more recent innovation is to use an electronic circuit to distinguish between the nystagmus oscillations and normal eye movements ${ }^{7}$. This approach is most useful in patients with pendular nystagmus. Eye movements are measured with an infrared sensor and fed to a phaselocked loop that generates a signal similar to the nystagmus but is insensitive to other eye movements, such as saccades. This electronic signal is then used to rotate Risley prisms, through which the patient views the world. When the Risley prisms rotate in synchrony with the patient's nystagmus, they nullify the visual effects of the ocular oscillations. Improvement and miniaturization of a prototype device may eventually yield spectacles that selectively cancel out the visual effects of pathological nystagmus ${ }^{7}$.

\section{MEDICAL PROCEDURES FOR WEAKENING THE EXTRAOCULAR MUSCLES}

Injection of botulinum toxin into either the extraocular muscles or the retrobulbar space has been reported to reduce nystagmus and improve vision in some patients ${ }^{8-11}$. Limitations of this approach are the short period of action (2-3 months), ptosis, and diplopia, which may be more annoying to patients than visual symptoms due to the worse in the non-injected eye, if the patient prefers to view with the injected eye. This is because botulinum toxin weakens all types of eye movement, not just the nystagmus. This paresis of normal movements stimulates the brain to make adaptive changes by increasing innervation that may worsen the nystagmus in the non-injected eye.

\section{APPLICATION OF SOMATOSENSORY OR AUDITORY STIMULI TO SUPPRESS NYSTAGMUS}

Various alternative treatments have been suggested for congenital nystagmus. Contact lenses can be beneficial, an effect that is not due to the mass of the lenses but is probably mediated via trigeminal afferents ${ }^{3,12}$. Electrical stimulation or vibration over the forehead or neck may suppress congenital nystagmus ${ }^{13}$, again possibly by an action on the trigeminal system, which receives extraocular proprioception. Similarly, acupuncture administered to the neck muscles may suppress congenital nystagmus in some patients ${ }^{14}$. Biofeedback has also been reported helpful ${ }^{15,16}$. The role of any of these treatments outside the laboratory, during natural activities, has yet to be demonstrated.

Box 2 Some current drug treatments for nystagmus (for details see Ref. 1)

\begin{tabular}{|ll|}
\hline Gabapentin & Scopolamine \\
Baclofen & Isoniazid \\
Memantine & Carbamazepine \\
Clonazepam & Barbiturates \\
Valproate & Alcohol \\
Trihexyphenidyl & Cannabis \\
Benztropine & Acetazolamide \\
\hline
\end{tabular}

\section{DRUG TREATMENTS FOR NYSTAGMUS}

Several drugs have been reported to suppress various forms of nystagmus and improve vision (Box 2), though the studies have mostly been uncontrolled or non-masked. Current concepts of the neurobiology of eye movements provide a rationale for three specific treatments, each of which has met with some success.

For us to hold the eyes steadily at an eccentric position (e.g. turned into right gaze), the brain must programme a tonic contraction of the extraocular muscles, otherwise the orbital tissue will pull back the eyes towards the centre ${ }^{2}$. This gaze-holding mechanism depends mainly on a network of neurons that lie in the medulla for horizontal gaze ${ }^{17}$ and in the midbrain for vertical gaze ${ }^{18}$. Pharmacological inactivation of the neural network in the medulla causes the eyes to drift to the centre and cause 'gaze-evoked nystagmus'. These studies have indicated that two 
neurotransmitters are important in this gaze-holding process: gamma-aminobutyric acid (GABA) and glutamate ${ }^{19,20}$. Theoretical and experimental evidence has suggested that some forms of nystagmus, such as the pendular nystagmus that occurs in multiple sclerosis, may arise from an instability in the gaze-holding mechanism ${ }^{21}$. The information served as the impetus for a controlled, double-blind trial of two agents with GABA effectsgabapentin and baclofen ${ }^{22}$. Most patients with pendular nystagmus benefited from gabapentin and elected to continue with this drug after the trial was completed. An open trial of a drug with glutamate effects, memantine, was also reported to offer improvement in patients with pendular nystagmus due to multiple sclerosis ${ }^{23}$.

In two rarer disorders, an understanding of pathogenesis suggested effective treatments. One is familial episodic vertigo and ataxia type 2 (a disorder of calcium channels), which responds to acetazolamide and calcium channel blockers ${ }^{24}$. The second is periodic alternating nystagmus, which follows lesions of the nodulus (vestibular cerebellum) and responds to baclofen ${ }^{25,26}$.

With improved knowledge of the pharmacology of the ocular motor system, further drug treatments are likely. Some agents, such as cannabis and alcohol $^{27}$, are not viable treatments during everyday activities because of their sideeffects; however, they may provide clues leading to new drug strategies. Before any agent can be regarded as an effective treatment for nystagmus, a controlled masked trial is essential ${ }^{28}$.

Acknowledgments Dr Stahl is supported in part by NIH grant K08 EY00356. Dr Leigh is supported by NIH grant EY06717, the Office of Research and Development, Medical Research Service, Department of Veterans Affairs, and the Evenor Armington Fund.

\section{REFERENCES}

1 Carpenter RHS. The visual origins of ocular motility. In: Cronly-Dillon JR, ed. Vision and Visual Function. Eye Movements, Vol 8. London: Macmillan, 1991:1-10

2 Leigh RJ, Zee DS. The Neurology of Eye Movements, 3rd edn. New York: Oxford University Press, 1999

3 Dell'Osso LF. Development of new treatments for congenital nystagmus. Ann N Y Acad Sci (in press)

4 Barton JJ, Cox TA, Digre KB. Acquired convergence-evoked pendular nystagmus in multiple sclerosis. J Neuroophthalmol 1999;19:34-8

5 Rushton D, Cox N. A new optical treatment for oscillopsia. J Neurol Neurosurg Psychiatry 1987;50:411-15

6 Yaniglos SS, Leigh RJ. Refinement of an optical device that stabilizes vision in patients with nystagmus. Optometry Vision Sci 1992;69:447-50
7 Stahl JS, Lehmkuhle M, Wu K, Burke B, Saghafi D, Pesh-Imam S. Prospects for treating acquired pendular nystagmus with servocontrolled optics. Invest Ophthalmol Vis Sci 2000;41:1084-90

8 Leigh RJ, Tomsak RL, Grant MP, et al. Effectiveness of botulinum toxin administered to abolish acquired nystagmus. Ann Neurol 1992; 32:633-42

9 Ruben ST, Lee JP, O'Neill D, Dunlop I, Elston JS. The use of botulinum toxin for treatment of acquired nystagmus and oscillopsia. Ophthalmology 1994;101:783-7

10 Repka MX, Savino PJ, Reinecke RD. Treatment of acquired nystagmus with botulinum neurotoxin A. Arch Ophthalmol 1994;112:1320-4

11 Tomsak RL, Remler BF, Averbuch-Heller L, Chandran M, Leigh RJ. Unsatisfactory treatment of acquired nystagmus with retrobulbar botulinum toxin. Am J Ophthalmol 1995;119:489-96

12 Dell'Osso LF, Traccis S, Abel LA, Erzurum SI. Contact lenses and congenital nystagmus. Clin Vis Sci 1988;3:229-32

13 Sheth NV, Dell'Osso LF, Leigh RJ, Van Doren CL, Peckham HP. The effects of afferent stimulation on congenital nystagmus foveation periods. Vision Res 1995;35:2371-82

14 Blekher T, Yamada T, Yee RD, Abel LA. Effects of acupuncture on foveation characteristics in congenital nystagmus. Br J Ophthalmol 1998; 82:115-20

15 Abadi RV, Carden D, Simpson J. A new treatment for congenital nystagmus. Br J Ophthalmol 1980;64:2-6

16 Ciuffreda KJ, Goldrich SG, Neary C. Use of eye movement auditory biofeedback in the control of nystagmus. Am J Optom Physiol Optics 1982;59:396-409

17 Arnold DB, Robinson DA. The oculomotor integrator: testing of a neural network model. Exp Brain Res 1997;113:57-74

18 Helmchen C, Rambold H, Fuhry L, Büttner U. Deficits in vertical and torsional eye movements after uni- and bilateral muscimol inactivation of the interstitial nucleus of Cajal of the alert monkey. Exp Brain Res 1998;119:436-52

19 Arnold DB, Robinson DA, Leigh RJ. Nystagmus induced by pharmacological inactivation of the brainstem ocular motor integrator in monkey. Vision Res 1999;39:4286-95

20 Straube A, Kurzan R, Büttner, U. Differential effects of bicuculline and muscimol microinjections into the vestibular nuclei on simian eye movements. Exp Brain Res 1991;86:347-58

21 Das VE, Oruganti P, Kramer PD, Leigh RJ. Experimental tests of a neural-network model for ocular oscillations caused by disease of central myelin. Exp Brain Res 2000;133:189-97

22 Averbuch-Heller L, Tusa RJ, Fuhry L, et al. A double-blind controlled study of gabapentin and baclofen as treatment for acquired nystagmus. Ann Neurol 1997;41:818-25

23 Starck M, Albrecht H, Straube A, Dieterich M. Drug therapy for acquired pendular nystagmus in multiple sclerosis. J Neurol 1997; 224:9-16

24 Baloh RW, Winder A. Acetazolamide-responsive vestibulocerebellar syndrome: clinical and oculographic features. Neurology 1991;41: 429-33

25 Furman JM, Wall C, III, Pang D. Vestibular function in periodic alternating nystagmus. Brain 1990;113:1425-39

26 Halmagyi GM, Rudge P, Gresty MA, Leigh RJ, Zee DS. Treatment of periodic alternating nystagmus. Ann Neurol 1980;8:609-11

27 Schon F, Hart PE, Hodgson TL, et al. Suppression of pendular nystagmus by smoking cannabis in a patient with multiple sclerosis. Neurology 1999;53:2209-10

28 Leigh RJ, Das VE, Seidman SH. A neurobiological approach to nystagmus. Ann N Y Acad Sci (in press) 